\title{
Availability of electronic libraries in the health sciences in the Arabian Gulf region
}

\author{
Karen Neves and Hakim Bishawi
}

\begin{abstract}
Health sciences libraries the world over have experienced an increase in the popularity and use of electronic resources in their collections. As the Internet has begun to invade even the remotest of areas, libraries in the health sciences are experiencing ever-increasing pressure to expand into the electronic environment. The Arabian Gulf region is no exception. In the Gulf Cooperation Council (GCC) countries (United Arab Emirates, Saudi Arabia, Bahrain, Qatar, Kuwait, and Oman) libraries are asked to serve the information needs of health practitioners with a diverse range of financial, electronic, and human resources. In some countries, both funding and infrastructure are excellent. In others, a lack of hardware, software, or financial resources have taken their toll on services. Through the use of online and fax questionnaires, this paper examines the availability of electronic resources in health libraries in the Gulf region and will look at the state of the art for such characteristics of digital libraries as a significant Web presence, ability to access resources at a distance, and the provision of library services using electronic media.
\end{abstract}

\section{Introduction}

While a small body of literature exists documenting the state of libraries and library cooperation in the Gulf Cooperation Council (GCC) countries, little has been published regarding health libraries in particular. Intergovernmental cooperation among GCC countries (United Arab Emirates (UAE), Saudi Arabia, Bahrain, Qatar, Kuwait, and Oman) has been well established since the inception of the group in 1981, but little formal study has been done on the growth and development of health sciences libraries in the region. For that reason, this survey was undertaken to provide a snapshot of the state of health libraries in the Arabian Gulf and, perhaps, to provide a benchmark by which further studies could gauge the progress of health libraries in these countries.

Before proceeding with a survey, the authors searched PubMed, Embase, Current Contents, and Google Scholar to identify any previous studies on health libraries or on library cooperation in general in the region. Very few studies were retrieved; only three studies regarding health libraries in $\mathrm{Ku}$ wait and Saudi Arabia were found. No studies were found covering libraries in all GCC countries.

Of the three studies retrieved on health libraries, two were done in Kuwait, one in 1984 [1] and the other in 2001 [2], and one study was conducted in Saudi Arabia in 1998 [3]. In general, these studies reflect the growth of electronic communication media but not the same exponential development as seen in Western countries over a similar time period. The 1984 study [1] briefly discusses the lack of access to

K. Neves. National Medical Library, P.O. Box 17666,

Al Ain, United Arab Emirates.

H. Bishawi. Tawam Hospital, P.O. Box 15258, Al Ain, United Arab Emirates.

${ }^{1}$ Corresponding author (e-mail: Karen.neves@uaeu.ac.ae).
MEDLINE in Kuwaiti libraries but refers to no other computerized resources. The 1998 study from Saudi Arabia [3] refers to "CD-ROM technology" and "commercial online databases", including MEDLINE. However, only six of the libraries surveyed $(50 \%)$ offered librarian-mediated searches via MEDLINE online, and 50\% had MEDLINE on CD-ROM. By the 2001 study [2], of 17 libraries in Kuwait, only 52.9\% of respondents provided online services, and $41.2 \%$ provided CD-ROM access. Interestingly, only four libraries $(23.5 \%)$ provided Internet access, and no hospital libraries offered this facility to its users. By 2001, it appears there was little growth in the availability of online resources.

Although the lack of previous studies encompassing health libraries in all GCC countries makes it difficult to judge the scope of growth regionwide, the results of this most recent survey seem to show an explosive growth in the availability of electronic resources in the Arabian Gulf region when compared with the 2001 study from Kuwait [2], with the majority of libraries (90\%) now offering electronic services, including Internet access, to their users. While the number of libraries offering electronic access has increased, so have the variety of available products and the platforms on which they are being offered, creating an exciting emerging market for e-resources with the potential for further growth.

\section{Methodology}

Notification of the survey was circulated to all known members of the health library community $(n=39)$ in every country of the Arabian Gulf region by e-mail, using the World Health Organization - Eastern Mediterranean Regional Office (WHO-EMRO) listserv, and by fax from lists of known medical libraries in the region. These lists were obtained from the document delivery departments of both the UAE National 
Fig. 1. Responses by type of library $(n=20)$.

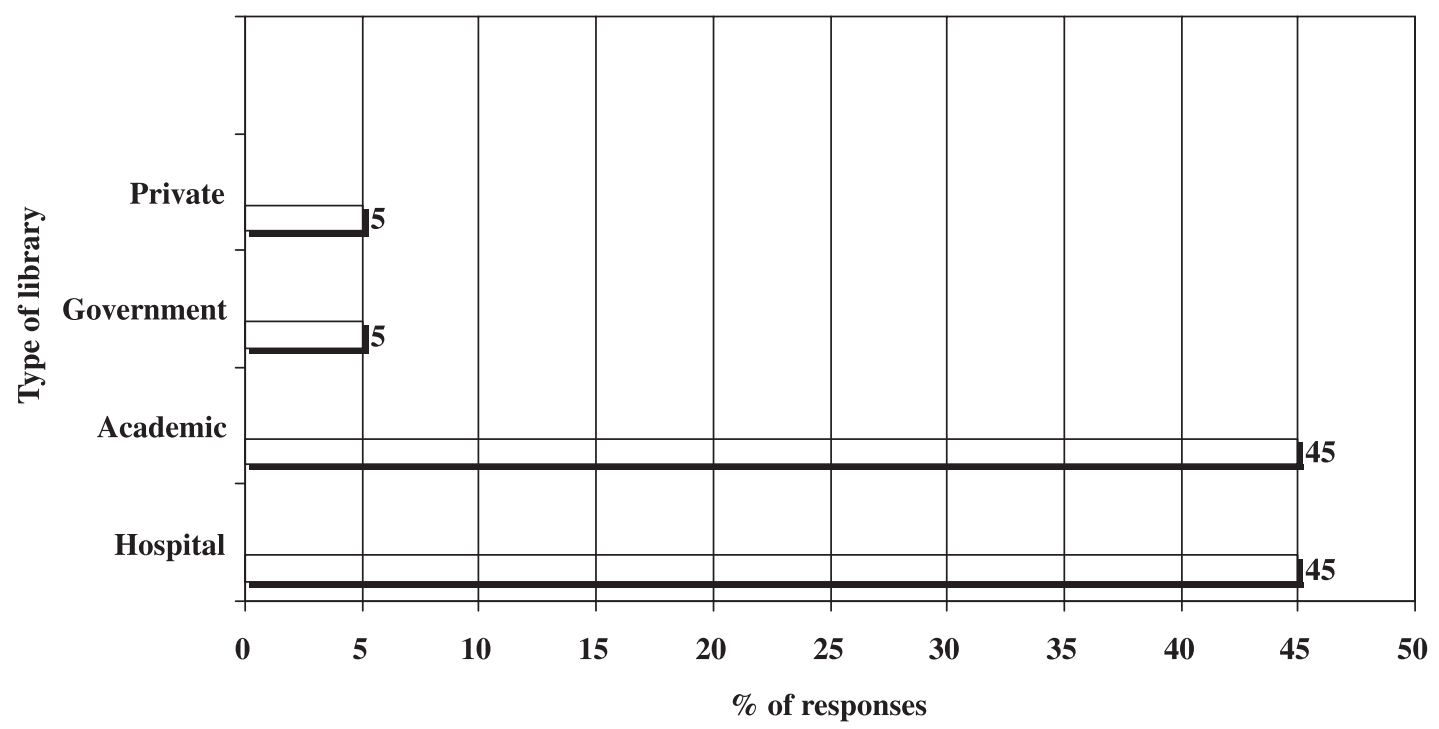

Medical Library and Tawam Hospital. Currently, no known up-to-date official list of health libraries in the GCC exists.

The questionnaire (Appendix A) consisted of 26 items, covering topics such as type of library, location, type of electronic resources held, remote access, virtual reference services, and participation in interlibrary loans. The questionnaire was distributed in English only, with an accompanying cover letter explaining the purpose of the study, data use, and confidentiality.

E-mail distribution included a full copy of the questionnaire (with a cover letter), which respondents could complete and e-mail or fax back to the authors. Alternatively, respondents could use a link to the Surveymonkey Web site (www.surveymonkey.com) to complete the survey on the Web. Fax distribution, chosen so that the survey could reach those libraries that may not have electronic access, included a cover letter and full copy of the questionnaire, with instructions requesting that respondents complete the questionnaire and fax it back to the authors.

A total of 22 responses were received: $45 \%$ online and $55 \%$ by fax. Two responses were excluded because of duplication (two institutions had completed the questionnaire twice). The total number of valid responses used in the analysis was 20.

\section{Results}

Of the valid responses, there was an even split between hospital and academic libraries; 45\% came from each sector (Fig. 1). One response came from a government library, and one came from a private company. Forty percent of responses were received from the UAE, followed by Saudi Arabia with $25 \%$, Oman with 16\%, Qatar with 10\%, and Bahrain and Kuwait with $5 \%$ each.

Ninety percent of the libraries indicated that they serve a population of doctors and other health professionals, while $15 \%$ also indicated that they serve students and faculty. This question allowed for multiple responses. Eighty percent indi-
Fig. 2. Staffing levels in libraries $(n=20)$.

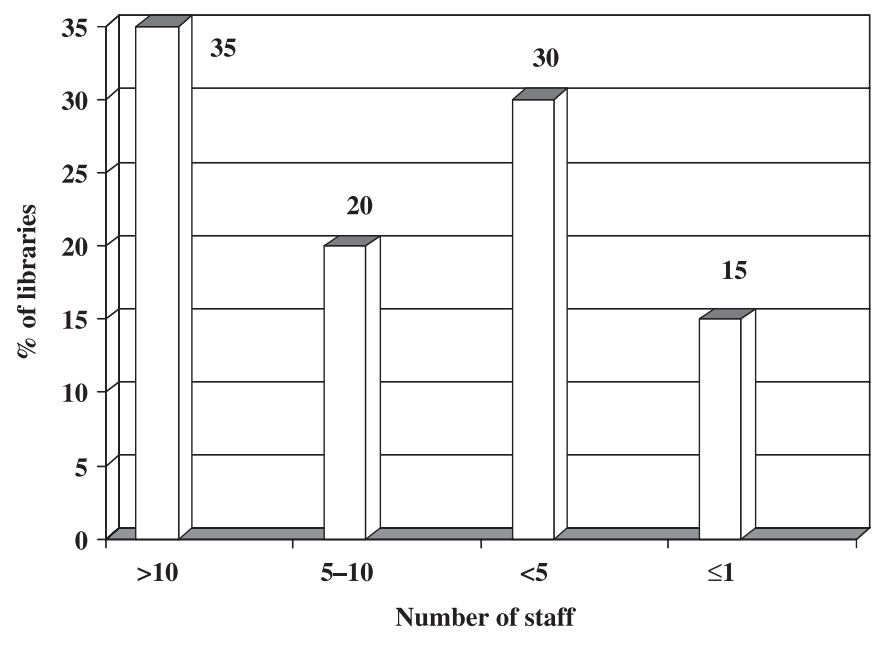

cated that they do not currently serve the information needs of patients.

Regarding the staffing levels among respondents, 35\% had more than 10 staff. Of these, $71 \%$ were academic libraries, and $29 \%$ were hospitals. Fifteen percent of respondents had only one staff member. Of these, $67 \%$ were hospitals, and $33 \%$ considered themselves academic libraries. The balance of respondents ranged between these two, with $30 \%$ of respondents having fewer than five staff and 20\% having 5-10 employees (Fig. 2).

\section{Profile of electronic resources}

Questions in this section of the survey were aimed at determining how many libraries had access to electronic resources, what type of products they were supplying, and how they were providing access. Ninety percent of respondents indicated that they have access to electronic resources. Of these, $58 \%$ said they offer remote access to their products.

Seventy percent of respondents have access to electronic books. Of the libraries that offer access, 35\% have fewer 
Fig. 3. Number of e-books to which libraries have access.

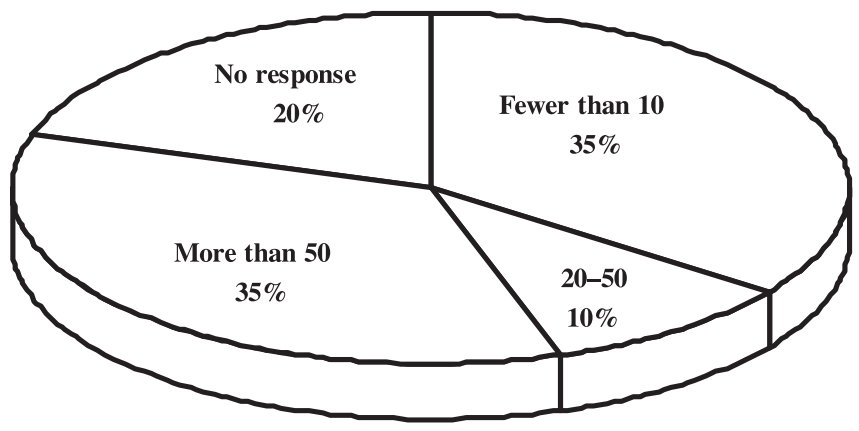

than 10 titles, $10 \%$ have $21-50$ titles, and $35 \%$ have more than 50 e-books (Fig. 3). Ninety percent of those surveyed indicated that they have electronic access to journals. However, $25 \%$ have fewer than 100 titles, 38\% have 100-500 titles, 6\% have 500-1000 titles, and $44 \%$ have more than 1000 titles (Fig. 4).

Only $65 \%$ of respondents reported that they have access to databases. Ten percent indicated that they have no database access, and $25 \%$ declined to respond to the question. Of the libraries with database access, 54\% indicated that they have access to fewer than 10 databases, $15 \%$ have access to $10-20,8 \%$ have access to $20-50$, and $23 \%$ have access to more than 50 databases. The authors believe this indicates a problem with this question, perhaps based on a language barrier or incomplete understanding of what constitutes a "database".

\section{Web presence}

Sixty-five percent of respondents indicated that they have a library Web site. Of those, 54\% have a webmaster, 23\% are served by their institution's information technology department, and $23 \%$ reported a library staff member as caretaker of the site.

\section{Electronic library catalogue}

Seventy-five percent of the libraries surveyed indicated that they have an electronic version of their online public access catalogue (OPAC), and $60 \%$ of those have a webcat. All respondents with webcats indicated that their catalogue was open access. Of those with webcats, $89 \%$ indicated that books could be renewed remotely using the OPAC.

\section{Library instruction}

This question allowed for multiple responses and was aimed at determining the extent and nature of the libraries' instructional programming. Respondents were asked whether they provided information literacy instructional programs and whether these programs were provided to individuals, small groups, large groups, or all of these. Eighty percent of the respondents reported conducting some form of library instruction, with $63 \%$ of those engaging in multiple forms of instruction. Thirty-eight percent were engaging in all forms of the instruction listed, but the majority $(81 \%)$ were doing individual and small group sessions only.

\section{Virtual reference}

Only $65 \%$ of respondents indicated that they were engaging in virtual reference. Of those, $100 \%$ were accepting and answering questions using e-mail, $23 \%$ of respondents use a Web form, and none were using virtual reference software.

\section{Document delivery}

Ninety-four percent of libraries reported that they use document delivery. The most common method for sending and receiving interlibrary loan (ILL) requests, with $88 \%$ of libraries using it, is e-mail. Only $18 \%$ of libraries are using Web forms. Of the libraries indicating participation in document delivery, 24\% reported using multiple formats for requests. To send and receive the requested articles, $71 \%$ of positive respondents use e-mail, 59\% use Ariel, and $12 \%$ use Web-based delivery systems. Thirty-five percent use both e-mail and Ariel (Fig. 5).

The majority of respondents $(33 \%)$ are exchanging services with other GCC medical libraries, while $8 \%$ also exchange services with other types of GCC libraries as well. The regional WHO library and the British Library are each used by $18 \%$ of respondents, while $15 \%$ use the Canada Institute for Scientific and Technical Information (CISTI) and $8 \%$ use the National Library of Medicine (US) (Fig. 6). Of the libraries participating in document delivery, $42 \%$ indicate being net lenders, with a greater number of items being sent from their collections, while 53\% say they are net borrowers. Five percent did not respond to this question.

\section{Discussion}

By far, the majority of health libraries in the Gulf region currently offer access to their library's electronic resources. In contrast to previous studies where a minimal number of libraries offered electronic access, more than $90 \%$ of respondents to this survey now report moving into the electronic environment with more than half of all respondents offering access remotely.

Although the questionnaire identified the types of libraries responding to the survey as well as the number of staff, the educational level of staff members - whether or not staff had Master's degrees and how many did — was judged by the authors to be a very sensitive cultural issue, so it was not addressed at this time. Staffing levels generally reflected the pattern in North America, with the majority of academic libraries $(71 \%)$ having more than 10 staff and far fewer hospital libraries (29\%) with the same number. However, $44 \%$ of hospital libraries have more than five staff members. Only $22 \%$ had solo librarians.

Sadly, very few libraries (20\% of those surveyed) offer services to nonhealth professionals. Whether this has to do with the policies of individual libraries or is dictated by cultural issues remains to be seen. In both libraries in which the authors work, it is extremely rare to see patients or members of the public in the library, although the UAE National Medical Library does serve nonhealth professionals as part of its mandate.

Electronic books and journals now seem to have become a common part of the suite of most libraries' resources, with 
Fig. 4. Number of e-journals to which libraries have access.

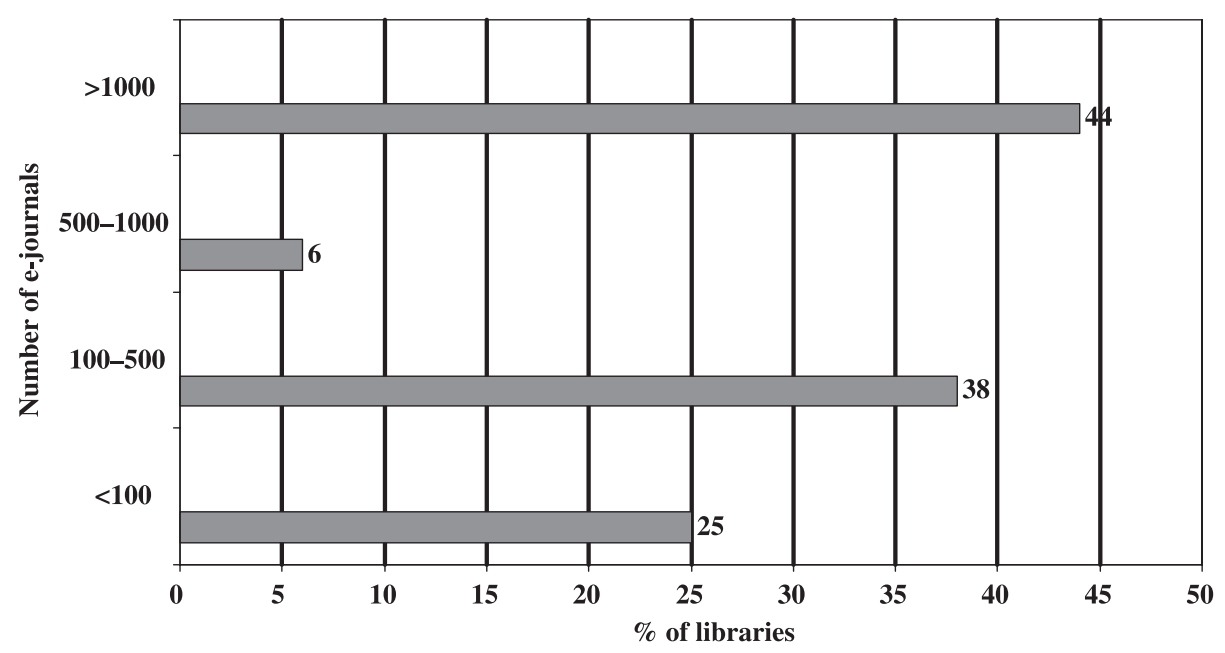

Fig. 5. Methods used by libraries for sending and receiving documents via interlibrary loan.

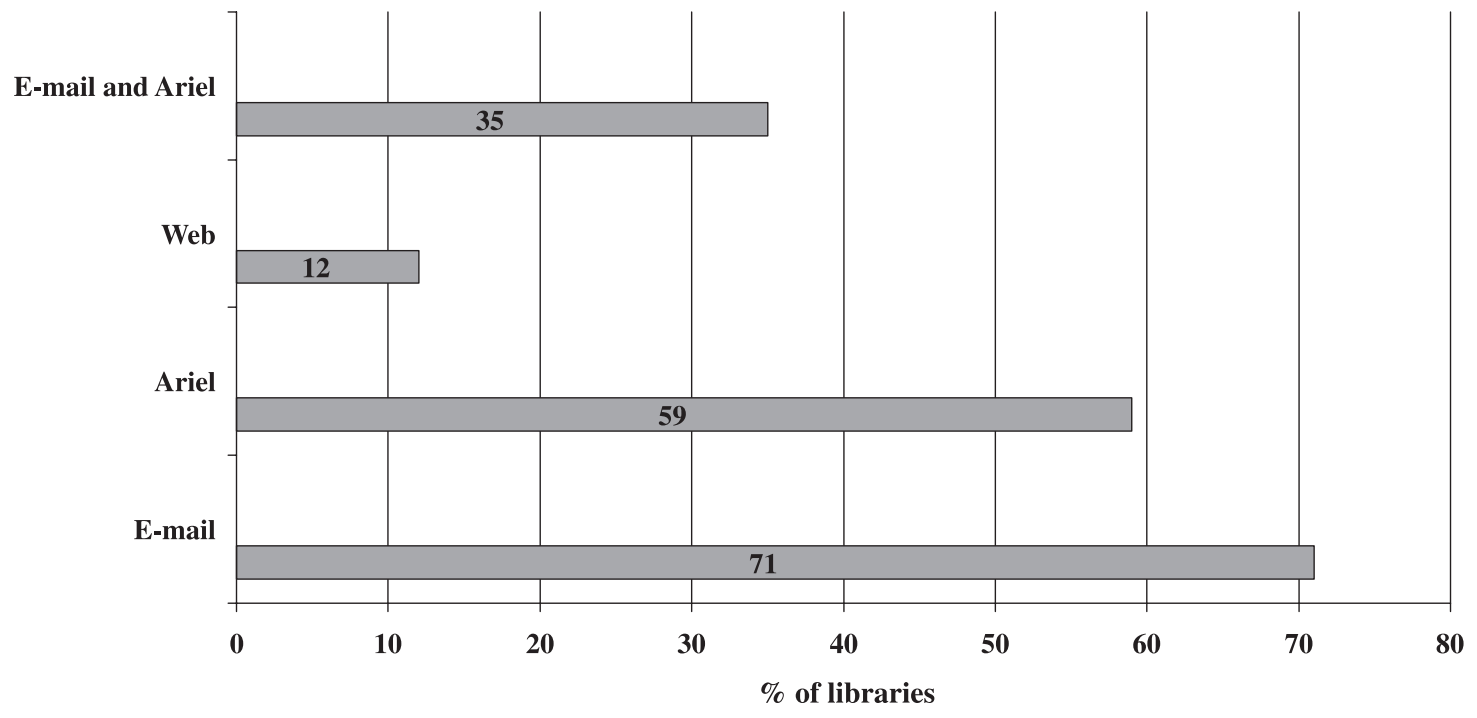

$90 \%$ of respondents having e-journals and $70 \%$ having e-books. The majority (44\%) of that $90 \%$ have more than 1000 e-journal titles. Of those with e-books, there is an even split between those who have fewer than 10 titles $(35 \%)$ and those who have more than $50(35 \%)$. It has been interesting to observe that there was some initial resistance at the UAE National Medical Library (NML) when e-books began to be added to the collection, with several patrons noting that they would not be well used because they were not convenient. With concerted efforts at product promotion and user education, these books have now become an indispensable part of the NML collection, with more titles being added regularly. It would not be unrealistic, in this case, to expect that $70 \%$ to grow in future surveys if this pattern holds true for other libraries.

The authors were disappointed in the response to the question regarding databases, with only $65 \%$ of the libraries indicating that they have access. Of these responses, the majority indicated that they have fewer than 10 databases. Only $23 \%$ indicated having more than 50. As noted, the authors feel that this suggests a problem with this question, having to do with either a language issue or an incomplete understanding of the meaning of the term "database".

A significant number of libraries now indicate having a general Web presence, including a Web OPAC. Sixty-five percent reported that they have a library Web site, with more than half of those having their own webmaster. Of the $75 \%$ who indicated having an electronic OPAC, 60\% have their OPAC on the Web, and all of these libraries have open access to their catalogue.

Libraries are also making good use of electronic resources for interlibrary loans and reference. Most commonly, documents are being sent, for ILL purposes, via e-mail but use is also being made of Ariel and Web forms. ILL is a good example of regional cooperation, as by far the greatest number of respondents (41\%) are exchanging documents within the GCC region. This number includes both GCC health sciences libraries (33\%) and GCC nonhealth sciences libraries $(8 \%)$. Outside of this, respondents are most commonly using the WHO, the British Library, and CISTI to obtain docu- 
Fig. 6. Document delivery partners.

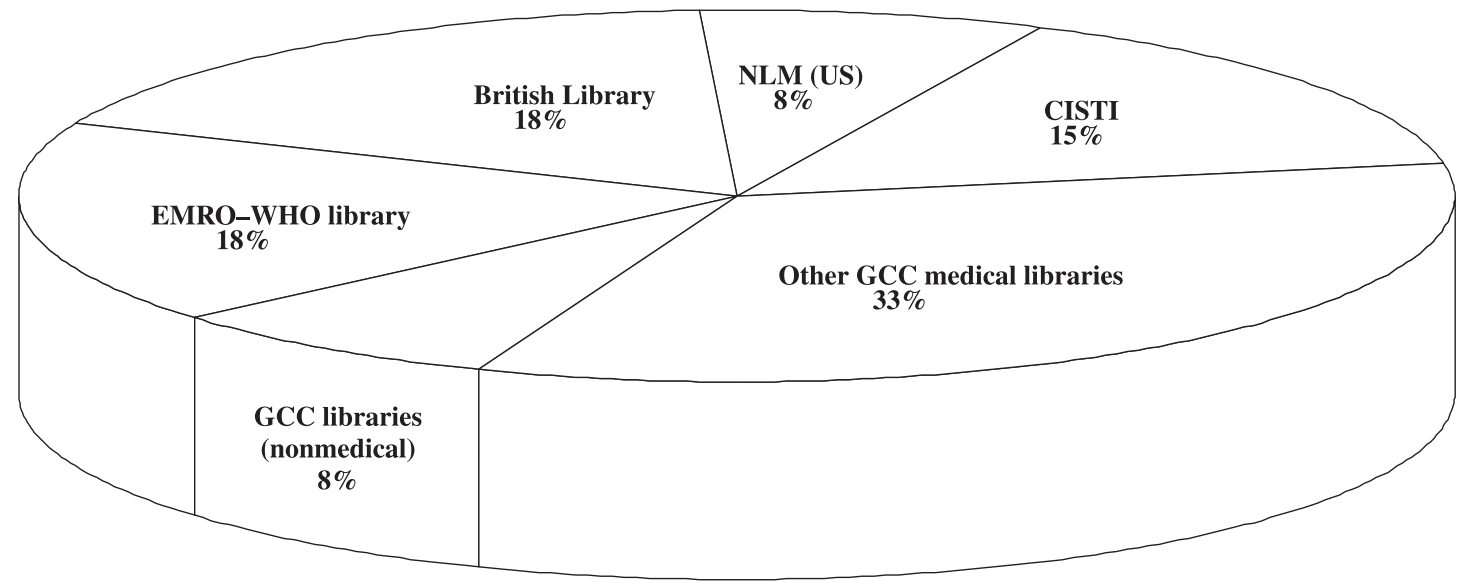

ments. No libraries are using virtual reference software to conduct reference transactions, although all respondents admitted sending and receiving questions via e-mail.

ILL has long been a good example of cooperation among GCC libraries and is well established through a network of libraries in this region [4,5]. Electronic resources in libraries other than those in the health sciences have been surveyed and, in general, the trends mirror those in our survey. Web catalogue use is on the rise, e-mail is the medium of choice for both reference and ILL, and Web forms are offered to supplement e-mail in these areas [6].

Although this region has seen conflict in recent years, and this has had effects on particular states within the Gulf, including depleted staff, loss of funding for libraries, disruption of technological growth and interstate cooperation $[7,8]$, library services seem to have recovered well. If the growth indicated in the current survey continues in health libraries, and with the advent of such new initiatives as the Dubai Healthcare City and partnerships with foreign institutions such as Harvard University (which is currently establishing a medical school and library in Dubai, UAE) and Johns Hopkins University (which has recently assumed management of one of the country's leading hospitals, Tawam Hospital in Al Ain, UAE), this region should continue to see exponential increases in the provision of services in health libraries.

\section{References}

1. Gorman Sullivan M, Brennen PW. Medical library services in Kuwait: History and future prospects. Bull Med Libr Assoc. 1984 Jan;72(1):12-7.

2. Al-Ansari HA, Al-Enezi S. Health sciences libraries in Kuwait: a study of their resources, facilities, and services. Bull Med Libr Assoc. $2001 \mathrm{Jul} ; 89(3): 287-93$.

3. Al-Ogla S. A study of hospital and medical libraries in Riyadh, Kingdom of Saudi Arabia. Bull Med Libr Assoc. 1998 Jan;86(1):57-62.

4. Siddiqui MA. Regional interlibrary loan network of Arabian Gulf academic libraries. Resource Sharing \& Information Networks. 1996;11(1/2):143-57.

5. Siddiqui MA. Adoption of Internet for resource sharing by the Gulf academic libraries. The Electronic Library. 2003;21(1):56-62.

6. Ahmed SS. Managing change to enhance Web-based services in the Arabian Gulf libraries. Online Information Review. 2002;26(4):265-70.

7. Aman MM. Libraries and information systems in the Arab Gulf states: After the war. Journal of Information Science. 1992;18:447-51.

8. Young HC, Ali SN. The Gulf War and its effect on information and library services in the Arabian Gulf with particular emphasis on the state of Bahrain. Journal of Information Science. 1992;18:453-62.

Appendix A appears on the following page. 


\section{Appendix A}

Survey on the availability of electronic resources in health libraries in the GCC

Principal investigators:

Hakim Bishawi, Librarian, Tawam Hospital, Al Ain, UAE

Karen Neves, Director, National Medical Library, Al Ain, UAE

What kind of library are you working in?

Hospital_

Academic (university or college)

Government ministry

Private company

Other, please specify

Which population of users do you serve?

Doctors and other health professionals

Patients

All of the above

Other, please specify

How many staff do you have?

No full time staff members

One full time staff member

Less than 5 staff members

5-10 staff members

More than 10 staff members

In which GCC country are you located?

Bahrain

Kuwait

Oman

Qatar

Saudi Arabia

UAE

Do you provide access to electronic library resources?

Yes

No

Which resources do you have? Please check all that apply.

Electronic books

Electronic journals

Databases 
What is the size of your electronic collection?

Electronic Books

Less than 10

$10-20$

$20-50$

More than 50

Electronic journals

Less than 100

100-500

500-1000

More than 1000

Databases

Less than 10

$10-20$

20-50

More than 50

Are these products available from outside your library?

Yes

No

Is your library catalogue available online?

Yes

No

Is your library catalog on the web?

Yes

No

Is it is possible to renew, reserve or request books using your catalog without coming to the library?

Yes

No

If your catalog is on the web, can everyone use it?

Yes

No

Does your library have a website?

Yes

No 
Do you have a full-time web master?

Yes

No

If no, who manages your website?

Do you offer any instruction in the use of the library's electronic collections?

Yes

No

If yes, what kind of teaching do you do? Please check all that apply.

Individual sessions

Small group sessions

Large group sessions

All of the above

Do you offer virtual or online reference services?

Yes

No

If yes, how do you offer the service? Please check all that apply.

Through email_

Through a web form

Through virtual reference software

Other (please specify)

Do you participate in electronic document delivery/inter-library loan of journal articles?

Yes

No

If yes, how do you send and receive requests? Please check all that apply.

Email

Docline

Web forms

Other (please specify)

How do you send and receive documents? Please check all that apply.

Email

Ariel

Web

Other (please specify) 
With which libraries are you exchanging ILL/DD services? Please check all that apply.

GCC medical libraries

Other GCC libraries

EMRO/WHO library

British Library

National Library of Medicine (USA)

CISTI (Canada)

Other (please specify)

Do you:

Borrow more materials than you send

Send more materials than you borrow

Does your library allow patients to use your online resources?

Yes

No 